\title{
Peripheral ossifying fibroma- A case report
}

\author{
Suhani Goel ${ }^{1}$, Sachit Anand Arora ${ }^{2}$, Shivjot Chhina ${ }^{3}$, Rupali Kalsi Mathur ${ }^{4}$ \\ ${ }^{1}$ PG Student, ${ }^{2} \mathrm{HOD},{ }^{3}$ Professor, ${ }^{4}$ Reader, Dept. of Periodontics, ITS Dental College Hospital and Research Center, Greater \\ Noida, Uttar Pradesh, India
}

*Corresponding Author:

Email: drsuhanigoel@gmail.com

\begin{abstract}
Gingival enlargement, also called gingival overgrowth, is the thickening of gum tissues that surrounds the teeth. The etiology of gingival growths may vary from reactive gingival enlargement in response to drugs to neoplastic lesions. Peripheral ossifying fibroma (POF) is a reactive lesion found on the gingiva and non-neoplastic in nature. This lesion is non neoplastic but occurs as a result of hyperplasia in response to oral microbes, dental plaque, occlusal trauma, local irritation, masticatory forces, dental calculus, and food debris. The purpose of this case report is to briefly overview clinical and histopathological features of POF in a 38 year old female patient and discuss the lesion in detail.
\end{abstract}

Keywords: Gingival overgrowth, Neoplasm, Peripheral ossifying fibroma, Hyperplasia.

\section{Introduction}

Peripheral ossifying fibroma (POF) is a reactive and non-neoplastic lesion formed on gingiva. It consists of fibrous tissue along with variable amounts of mineralized material resembling bone. Numerous factors such as local irritation, microorganisms, masticatory forces, minor trauma, trapped food debris, microbial plaque, calculus and iatrogenic factors have been proposed to be causative in the development of the lesion. ${ }^{1}$ Clinically, it appears as a nodular mass which may be sessile or pedunculated. It is more commonly seen in 1 st and 2 nd decades and has a preponderance for the maxillary arch and in the incisor cuspid region of females. ${ }^{2}$

\section{Case Report}

A 38 year old female patient reported to the Department of Periodontics with a chief complaint of a slowly growing, painless, gingival growth in the maxillary posterior region extending from 25 to 27 since 6 months. On eliciting the history, the patient first noticed the swelling 3 months back, which was insidious in onset. There was no history of pus, blood or watery discharge or color change noted over the swelling. On inspection, the overgrowth was dome shaped; measuring approximately $1.5 \mathrm{~cm} \times 2 \mathrm{~cm}$ in size and the overlying mucosa was reddish pink in color (Fig. 1). No ulceration was observed. On palpation, the growth was non-tender, firm in consistency and not fixed to the underlying tissue. Bleeding on probing was present. Considering the history and the examination findings, the differential diagnosis included Peripheral giant cell granuloma and Peripheral Ossifying fibroma. Surgical excision of the lesion was performed under local anesthesia and the tissue was subjected to histopathological evaluation. (Fig. 2).

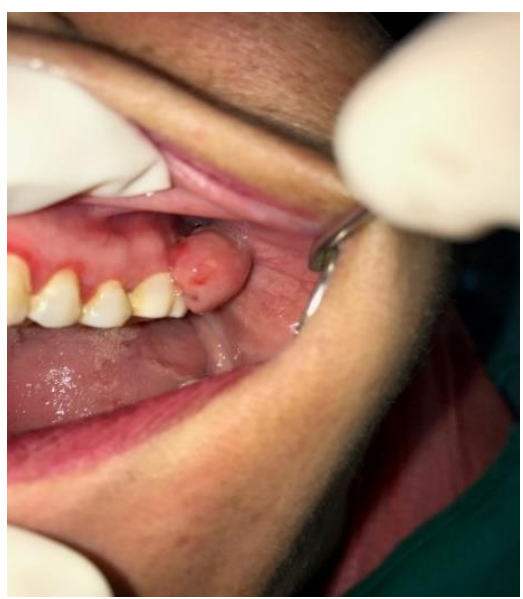

Fig. 1: Intraoral inspection shows the dome shaped growth on the maxillary posterior gingiva

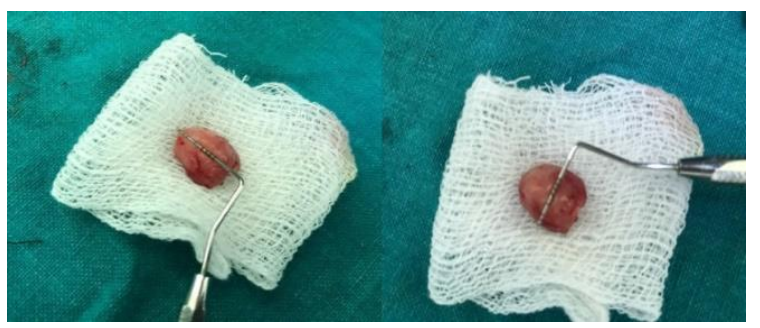

Fig. 2: Biopsy specimen sent for histopathological evaluation

\section{Histopathological Examination}

The histopathological sections revealed an oedematous, fibrocellular stroma with thick intersecting trabeculae of woven bone. The woven bone showed intact osteolytic lacunae and few reversal lines (Fig. $3 a)$. The connective tissue stroma exhibited dense bundles of collagen fibres interspersed with randomly arranged plump mesenchymal cells with an ovoid vesicular nucleus and indistinct cytoplasmic borders. Moderate numbers of chronic inflammatory cells were 
also noted within the stroma. A fibrinopurulent membrane with areas of parakeratinised stratified squamous hyperplastic epithelium was seen encasing the lesion (Fig. 3b).

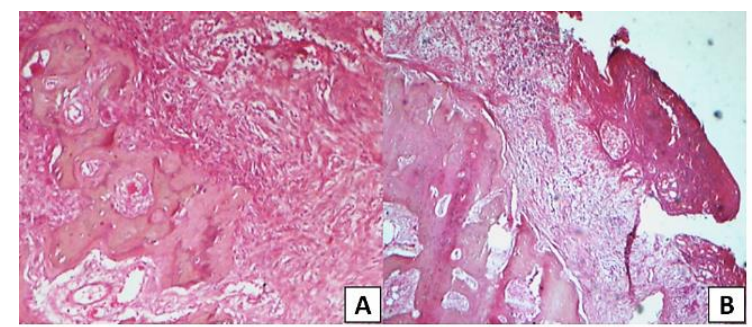

Fig. 3: (a) Trabeculae of woven bone merging into the surrounding collagenous connective tissue stroma. The bony trabeculae show basophilic reversal lines. (b) Parakeratinized stratified squamous epithelium encompassing the lesion

\section{Treatment}

The treatment options for peripheral ossifying fibroma include excision of tissue with laser, electrocautery etc. In the present case, after the elimination of local etiological factors such as plaque and calculus via scaling and root planning (SRP), the patient was recalled after 15 days. Local anaesthesia (1:80,000 adrenaline) was administered and gingivectomy incision was given to achieve complete excision of the gingival growth. To prevent recurrence, root planing and thorough curettage was performed. The patient was educated and motivated to maintain proper oral hygiene. The healing was uneventful when evaluated after 15 days (Fig. 4).

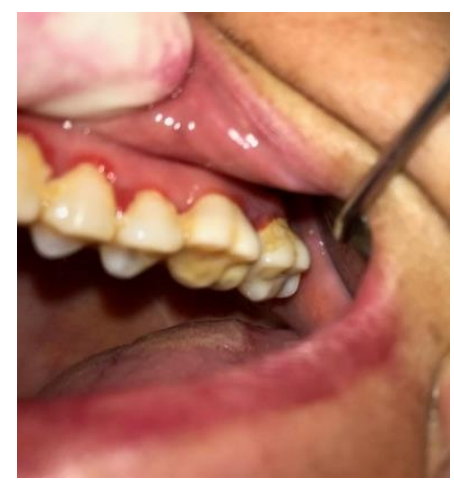

Fig. 4: Post-Operative examination after 15 days shows uneventful healing

\section{Discussion}

The term peripheral ossifying fibroma was coined by Eversole and Robin in $1972 .^{3}$ Peripheral ossifying fibroma is defined as any "solitary growth on the gingiva thought to arise from periodontal ligament and more commonly at the region of interdental papillae". 4 Etiological factors include subgingival plaque, calculus, dental appliances, faulty dental restorations or trauma. Females are more affected than males with a ratio of
$5: 1 .^{5}$ It is a relatively common growth of gingiva and is considered to be reactive in nature rather than neoplastic. ${ }^{6}$ Clinically, POF appears as a slow growing solitary mass which is either pedunculated or sessile, the surface is usually smooth or ulcerated and the color ranges from red to pink, measuring about $1-2 \mathrm{~cm}$ in diameter. The origin of these lesions in the periodontal ligament cells is considered to be because of:

1. Gingival tissue present close to the periodontal ligament.

2. Oxytalan fibers.

3. The age distribution of the lesions which is inversely proportional to the number of permanent teeth lost.

4. POF fibrocellular response. ${ }^{7}$

Hormonal influence may also play a role, as it has a higher incidence among females, being observed more often in the second decade and declining incidence after the third decade. ${ }^{8} \mathrm{POF}$ is a proliferative fibrous lesion of the gingival tissue which results in functional and esthetic problems. The mineralized component of peripheral ossifying fibroma varies from $23 \%$ to $75 \% .^{9}$ The radiographic appearance of the lesion is variable and the lesion may either show no change to scattered radiopaque foci in the center of the lesion. The density of such calcifications depends upon the degree of mineralization; however not all lesions show calcified masses. ${ }^{9}$ The treatment includes surgical excision followed by oral prophylaxis. The average time interval for the first recurrence has been reported to be 12 months. Peripheral ossifying fibromas are known to have a high recurrence rate of $8-20 \%$ which necessitates periodic follow up of the lesion. The healing was uneventful when evaluated after 15 days. This high recurrence rate is suggested to be due to incomplete excision, and or persistence of local factors. ${ }^{10}$

\section{Conclusion}

Peripheral ossifying fibroma is a slow progressing lesion and therefore it goes unnoticed at times. Accurate identification of the lesion and differentiation from other benign odontogenic and benign epithelial tumors should be given importance. High recurrence rate of the lesion also necessitates periodic follow up and evaluation.

\section{References}

1. Mohiuddin K, Priya NS, Ravindra S, Murthy S. Peripheral ossifying fibroma. J Indian Soc Periodontol 2013;17(4):507-9.

2. Cuisia ZE, Brannon RB. Peripheral ossifying fibroma - a clinical evaluation of 134 pediatric cases. Pediatr Dent 2001;23(3):245-8.

3. Eversole LR, Rovin S. Reactive lesions of the gingiva. J Oral Pathol 1972;1:30-8.

4. Shafer WG, Hine MK, Levy BM. Benign and malignant tumors of the oral cavity. Textbook of Oral Pathology, 6th ed. India:Elsevier;2009. p. 80-219. 
5. Gardner DG. The peripheral odontogenic fibroma: an attempt at clarification. Oral Surg Oral Med Oral Pathol 1982;54(1):40-8

6. Kumar V, Abbas AK, Aster JC. Robbins and Cotran Pathologic basis of disease. $7^{\text {th }}$ ed. Philedelphia: Elsevier Health Sciences;2012.

7. Kumar SK, Ram S, Jorgensen MG, Shuler CF, Sedghizadeh PP. Multicentric Peripheral Ossifying Fibroma. J Oral Sci 2006;48(4):239-43.

8. Kenney JN, Kaugars GE, Abbey LM. Comparison between the peripheral ossifying fibroma and peripheral odontogenic fibroma. J Oral Maxillofac Surg 1989;47(4):378-82.

9. Farquhar T, Maclellan J, Dyment H, Anderson RD. Peripheral ossifying fibroma: a case report. J Can Dent Assoc 2008;74(9):809-12.

10. Das UM, Azher U. Peripheral ossifying fibroma. J Indian Soc Pedod Prev Dent 2009;27(1):49-51. 